\title{
Does Prostate Cancer Begin in the Prostate? Key Predictors of Having Disease
}

\section{Nnamdi Orakpo*}

Department of Aging and Disabilities, University of North Texas Denton, TX, USA

\begin{abstract}
The purpose of this exploratory study was to identify the key predictors of prostate cancer; such study may lead to the development of appropriate interventions and prevention. Previous epidemiological studies have found these following factors to be key predictors for being diagnosed with hormone-associated carcinoma such as prostate cancer: age, ethnicity, physical activity, family history, diet, sleep amount, marital status, and having another form of carcinoma. Many studies have included results only for men over the age of 65, however, prostate cancer is claiming the lives of many African American, Hispanic and White American men over the age of 35, and younger men are more likely to battle it if they are genetically predisposed. The sample population $(\mathrm{N}=21,646)$ was selected because men aged 35 or over has the highest prevalence of prostate cancer. Of this sample, 619 reported having prostate cancer, and 1,401 reported having some other type of cancer. This study employs a logistic regression model using SAS $B$ and utilizes the National Health Interview Survey data set and a multivariate analysis of the years 2006, 2007 , and 2008. To improve the quality of future research the methods need modification, the subpopulation being studied should be larger, and the studies should be longitudinal. This particular study found the aforementioned factors to be critical in predicting prostate cancer. Maximum sun exposure was also found to be related to prostate cancer. Key predictors for prostate cancer diagnosis are: age, ethnicity, having some other cancer and maximum sun exposure, and education. Though previous studies have found physical activity, sleep amount, and occupation to be beneficial in reducing the risk for prostate cancer, it was not confirmed in this particular study.
\end{abstract}

Keywords: Age; Ethnicity; Physical activity; Family history; Sleep amount; Marital status; Maximum sun exposure; Some other cancer; Education

\section{Introduction}

Successful aging is a concept that promotes engagement and productivity of an individual from middle age to old age. Globally, people are living longer and enjoying more physically and mentally healthy lives [1]. In the field of aging, more emphasis and research has been done on the successful aging theory. The World Health Organization (2002) asserts successful aging means having physical and mental well-being. It is indicative of an older adult's ability to remain independent and productive [2]. This concept is multidimensional and currently no single theory independently represents the authority on successful aging. Theorists such as Walker et al. [1] present a model that emphasizes the importance of remaining physically active. Physical activity is an asset to an individual's mental and physical health [2]. At times, some ailments can prevent an individual from being physically active which can counter successful aging. Mosher et al. [3] have shown that physical activity and exercise, among other variables, can be influential in reducing the risk of illness. Other factors may include occupational physical activity, age, diet, ethnicity, education, and family history.

Many chronic illnesses, namely carcinomas, are prevalent among men and women in the United States, preventing millions from aging successfully. In the United States, there are approximately 11 million Americans living with cancer, and $61 \%$ of those living with cancer are 65 years of age or older [5]. Globally, prostate cancer continues to plague the lives of millions of men. A large study of 15 million participants from five Nordic countries found 340,000 cases of prostate cancer, and this is almost $33 \%$ of all incident cancer among men in these countries [4]. The incidence has tripled since 1960, namely in Finland, Norway, and Sweden [4]. In comparison to the Nordic countries, the American Cancer Society [5] reported an estimate of 217,730 cases of prostate cancer that were incident in 2010 in the United States, expecting 32,050 to die from the disease in the same year. Earlier, during 2006, over 203,000 men were diagnosed, while more than 28,000 died from prostate cancer (CDC, 2010). The incidence of prostate cancer is lower in Japan than it is among Japanese men living in Hawaii [6]. The higher incidence among Japanese men in America may be due to a high fat diet in the United States and the low intake of isoflavones [6].

Biologically, isoflavones are phytoestrogens (chemical in plants) that behave like hormones. They have anti-estrogenic functions that occur in the reproductive tissues and could contribute to lowering the risk for hormone-related carcinomas (Linus Pauling Institute, 2010).

Prostate cancer incident is the highest among African American men (CDC, 2009). This is thought to be attributed to socioeconomic conditions, such as lower socioeconomic status, being underinsured or uninsured, lack of access to educational resources and other disparities in healthcare that are prominent among minorities (CDC, 2010). For example, Konety et al. [7] found that the lack of educational materials regarding prostate cancer was a hindrance to the efficient delivery of healthcare and counseling to men; this lack of resources also prevents effective patient-provider communication.

\section{Purpose of the study}

Prostate cancer is the most prevalent carcinoma among men in

*Corresponding author: Nnamdi Orakpo, Biomedical Gerontologist \& Doctor of Medicine Candidate, University of North Texas Denton, TX, Department of Aging and Disabilities, Department of Medicine, Universidad Autonoma de Guadalajara School of Medicine, Mexico, USA, Tel: 469-274-2308; E-mail: w.nnamdi.orakpo@gmail.com

Received June 03, 2013; Accepted February 06, 2014; Published February 10 2014

Citation: Orakpo N (2014) Does Prostate Cancer Begin in the Prostate? Key Predictors of Having Disease. J Gerontol Geriat Res 3: 146. doi:10.4172/21677182.1000146

Copyright: () 2014 Orakpo N. This is an open-access article distributed under the terms of the Creative Commons Attribution License, which permits unrestricted use, distribution, and reproduction in any medium, provided the original author and source are credited. 
the United States, and more research is necessary in order to identify what factors are key indicators of having prostate cancer among men 35 years of age and older. Not enough research includes middle-aged men in prostate cancer studies and very little evidence supports that prostate screening is the most efficient. Since the cause for prostate cancer has yet to be identified, it is imperative that many variables be measured to determine the key indicators that have the most impact on prostate cancer diagnosis, and to determine what steps should be taken to design preventive health programs that will assist in the successful aging of men in the United States.

\section{Statement of the problem}

The goal of the study is to identify the key risk factors for that predict men age 35 and older are more likely to be diagnosed with prostate cancer. The variables include age, ethnicity, and the following lifestyle factors: physical activity, marital status, sleep, sun exposure, and education. The aforementioned variables have been found in previous studies to affect the likelihood of having prostate cancer. From the years 2002-2006, the median age at diagnosis was 68 , indicating that $50 \%$ of the men who were diagnosed during these years were 68 or younger when they developed prostate cancer (American Cancer Society, 2010). This study is necessary to further build the research and provide implications and useful information about prostate cancer screening for men from middle age to old age.

\section{Significance of the problem}

Prostate cancer is most prevalent in older men [8]. According to the American Cancer Society in 2009, more than 192,000 American men were diagnosed with prostate cancer, while more than 27,000 men were expected to die from it in the same year. Approximately $50 \%$ of men 80 years of age and older can expect to battle prostate cancer and few research studies include middle-aged men 35 and older [5]. This study is necessary because it includes results for men from this underrepresented age group. Many studies only reveal results for older men over the age of 60 , and there are very few implications for middleaged men on how to prevent or be screened for prostate cancer into old age (American Cancer Society Facts and Figures, 2010).

\section{Assumptions}

Being an African American increases the likelihood that one will have prostate cancer because of socioeconomic issues and malnutrition [5]. Engaging in any amount physical activity may decrease the likelihood that a man would develop prostate cancer since 33 percent of cancer deaths in the United States are associated with sedentary lifestyles, poor nutrition and obesity [5]. Being married may increase the likelihood that man would have early detection of prostate cancer since those with a spouse may be more encouraged to do routine prostate exams, and therefore carcinoma are more detectable; research finds higher comorbidity among Black and unmarried men, which are least likely than other groups to seek therapy [9]. An ample amount of sleep a man acquires may reduce the likelihood that a man would have prostate cancer due to the idea that melatonin hormone is generated during sleep, and melatonin may be a tumor suppressor or, protective against prostate cancer development [10]. Having more education may increase the likelihood of early detection if a man had prostate cancer because those with more education may be more likely to be screened early and frequently [5].

\section{Review of Literature}

\section{Overview of the prostate}

Prostate cancer has claimed the lives of many men and continues to do so, and many can expect to battle this disease later in life. What is the prostate? The prostate is an integral part of the male reproductive system underneath the bladder, but preceding the rectum; its duty is to generate a fluid ingredient within the semen. The urethra releases urine from the bladder. As the prostate enlarges it produces pressure upon the urethra, causing issues with release of semen and urine. Figure 1 is a diagram of the prostate anatomy.

\section{Parameter of literature review}

Prostate cancer and age: Prostate cancer affects men of all ages and all races (CDC and Cancer and Prevention and National Cancer Institute, 2009). Prostate cancer is most prevalent in older men, and being screened and managing prostate issues becomes more of a priority as age increases. Notably, about $65 \%$ of all prostate cancer cases are diagnosed in men over the age of 65 [11]. According to the American Cancer Society, in 2009, more than 192,000 men were diagnosed with prostate cancer and it was expected that more than 27,000 deaths would result from it within the same year (American Cancer Society, 2009). This is a decrease in incidence, and an increase in mortality compared to that of 2005 , which could be due to the strong correlation between age and prostate cancer and the increase in human longevity; it could also be attributed to the increase in awareness of the disease pushing more men to engage in preventive prostate health practices, such as early and frequent screenings. In 2010, an estimated 217,730 American men are expected to be diagnosed with prostate cancer, while more than 32,050 men are expected to die from it in the same year [5]. Considering age differences, approximately $50 \%$ of men who are 80 and older can expect to battle prostate cancer. Research and autopsy reports find that $70 \%-90 \%$ of men over the age 80 were found to have prostates infected with cancer without any knowledge of it, and without their physician knowing [5]; some cancers spread rapidly, but most cancer cells grow slowly. Additionally, dormant prostate cancer is most common among men in this age cohort (ESMO, 2005). Currently, more research is warranted to fully grasp the preventive measures, the cause, the onset, and the treatments for prostate cancer in middle aged men age 35 and older. Men would be able to age more successfully if more health information on how to maintain prostate health is available to them at a younger age (age 35). Gallus et al. [8], states that prostate cancer studies done on middle-aged men are few, and that most significant findings involve men older than 60 years of age.

Currently, there is no definitive information revealing the cause of prostate cancer, however, research [8], shows that a family history of the disease increases the risk of prostate cancer at a younger age.

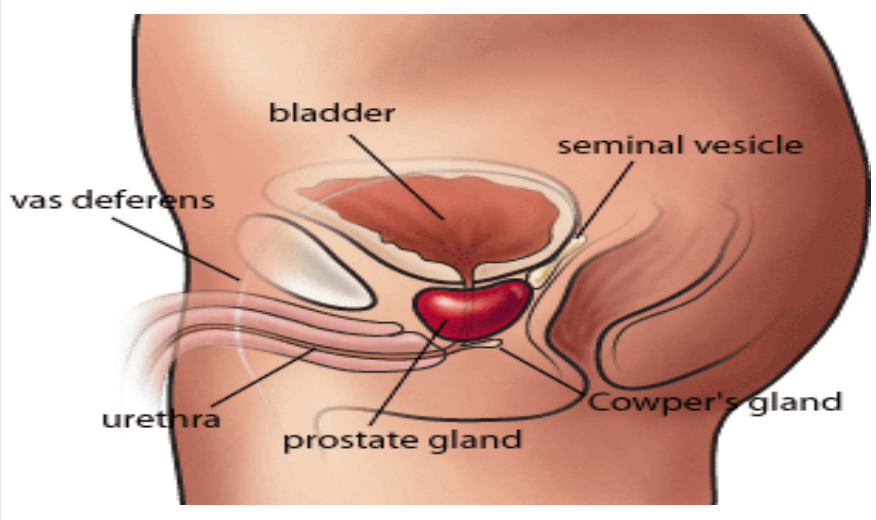

Figure 1: Prostate anatomy. 
Citation: Orakpo N (2014) Does Prostate Cancer Begin in the Prostate? Key Predictors of Having Disease. J Gerontol Geriat Res 3: 146. doi:10.4172/2167-7182.1000146

Page 3 of 12

On average, men in Europe are 71 when diagnosed with prostate cancer; in all of Western Europe and Nordic countries it is the most common type of carcinoma (ESMO, 2005). As age increases, there may be an increase in the amount of Prostate-Specific Antigen (PSA) in the blood; an elevated level of PSA may indicate prostate cancer [12]. Prostate-specific antigen (PSA) tests become critical as age increases. A correlational research study conducted by Chiu et al. [13] found that as age increased, men were less willing to receive PSA screenings. Furthermore, men that have a seemingly regular-sized prostate gland and whose PSA levels are less than 4 micrograms per liter, have a $15 \%$ chance of developing prostate cancer; men with a PSA level that falls between four and 10 micrograms per liter have a $25 \%$ chance of being diagnosed with prostate cancer, and finally, a PSA above 10 is indicative of a $67 \%$ chance of being diagnosed with prostate cancer.

\section{Prostate cancer and race \& ethnicity}

Ethnicity is a factor that is strongly associated with prostate cancer incidence. Each year thousands of men become victims of prostate cancer. The American Cancer Society (2009) estimated that in 2010, 192,000 were diagnosed with prostate cancer, while 27,000 men would have died from prostate cancer in the same year. Furthermore, an estimated increase in incidence $(217,730)$ and increase in mortality $(32,050)$ will occur in 2010 in the United States [5]. Internationally, men who are descendants of sub-Saharan Africa are at a substantially higher risk for having prostate cancer, whereas Asian descendants have the lowest likelihood of having prostate cancer. Asian descendants in Asia are much less likely to have prostate cancer than Asian in the United States [14], but Asian migrants in the United States are less likely to have prostate cancer than Caucasian Americans [15]. Many researchers, Breen et al. [16], Hoffman et al. [17], and Etzioni et al. [18], find that African American men are less likely than Caucasian American men to be screened for prostate carcinoma. According to the Center for Disease Control [19,20], since 1975, African Americans have had and continue to have the highest incidence of prostate cancer.
Caucasian American men had the second highest incidence, followed by Latinos, Asian/Pacific Islander and lastly, Native American men [20]. Figure 2 shows the rates of incidence from 1975-2005.

In the United States, prostate cancer claims more lives of men than any other cancer (CDC and Prevention and National Cancer Institute, 2010). Though there are many protocols for prevention, detection, research, and treatments for prostate cancer, many things remain undiscovered [5]. Regarding cancer and ethnicity in general, the death rate from cancer for African Americans is 34 percent higher than that of whites [5]. Death rates varied by ethnicity from 1975-2005. For example, African American men were also most likely to die from prostate cancer, specifically, than all other ethnic groups. Caucasian American men had the second highest mortality rate followed by Native Americans, Hispanic and then Asian/Pacific Islander [20]. Various factors determine screening practices [16]. The American Cancer Society [5] found that higher death rates among African Americans were attributed to risk factors such as lower socioeconomic status. According to Liu et al. [21] and Roetzheim et al. [22], men are more likely to have advanced prostate cancer due to lower socioeconomic status; lower socioeconomic status is associated with disparities such as lack of access to healthcare, lack of insurance, low income, and lower levels of education.

\section{Prostate cancer and marital status}

Marriage may be a critical element for men over the age of 35 who are at-risk for prostate cancer or who are battling prostate cancer. Recent research [23] finds solid spousal support is a key factor for enhancing health-related quality of life for men with prostate cancer. Marriages or partnerships that are solid and supportive may prove valuable in reducing stress and anxiety, and could help maintain psychological stability [24]. Research finds that men who have been divorced or separated are at a significantly higher risk for having prostate cancer than men who are married [25]. Men older than 35 who are married or have the attentiveness and nurturing of a spouse

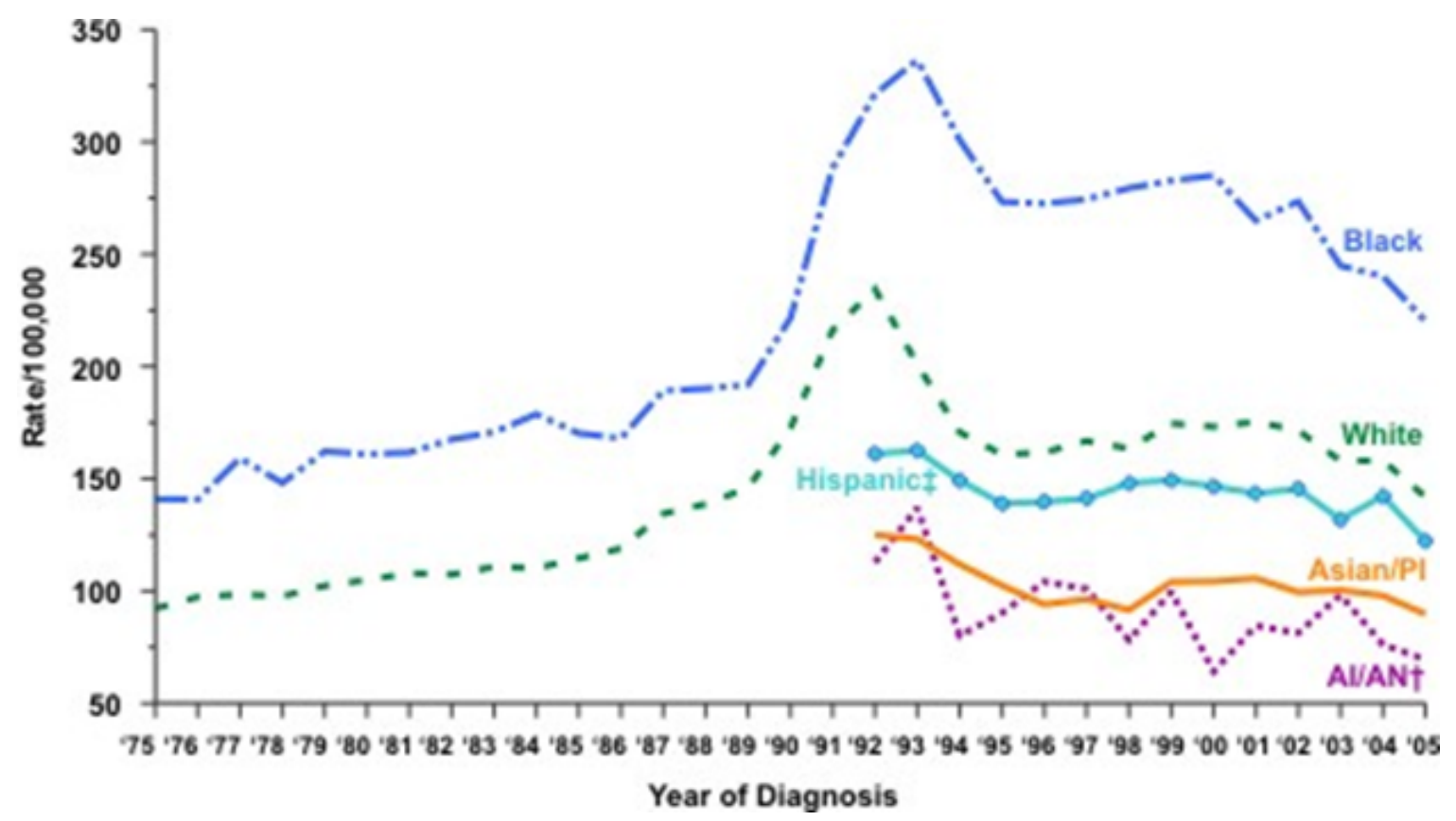

Figure 2: Incidence rates of prostate cancer, 1975-2005 (from Surveillance, Epidemiology, and End Results (SEER) Program, National Cancer Institute (NCI) 1975-1991 = SEER 9; 1992-2005 = SEER 13). 
may be encouraged to have PSA screenings and have assistance with monitoring lifestyle modifications. Being married has been shown in prior studies to benefit men with prostate cancer, and it can lower the overall risk for having the disease.

\section{Lifestyle variables}

Several lifestyle factors have been associated with the risk of prostate cancer. Although, no single factor has shown to be the catalyst to the onset of prostate cancer, a culmination of the following lifestyle variables are associated: a) light-moderate physical activity b) strengthening exercise, c) type of work, c) sleep amount, d) sun exposure, e) diet, and f) education. These measures are independent variables in the study.

Physical activity: Physical activity can prove to be valuable at any age and it may help purport a positive health status. In order to examine the effect of physical activity, the distinction is made between degrees of physical activity, i.e. light, light-moderate, vigorous, and strengthening exercises.

Research shows that moderate-vigorous physical activity, such as sports, is effective in decreasing the risk for the development of all carcinoma [1]. A study [7] found a strong inverse association between physical activity and prostate cancer. In the same study, Gallus [8] concluded that the effects of physical activity were inconsistent. Wannamethee et al. [1] discovered that the regular engagement in vigorous physical activity decreases the risk for prostate cancer among middle-aged men.

Exercise has been identified by researchers as a primary tool for improving overall quality of life. Among older long-term prostate cancer survivors, Mosher et al. [3] finds that consistent moderateto-vigorous exercise done weekly improves physical function, health perception, and quality of life among cancer survivors older than 60 years. One study shows that vigorous physical activity increases the androstenedione hormone levels in the body. It is thus imperative that middle-aged and older adults engage in customized exercise regimens. One study found correlations between physical activity and education level. An increase in age and lower education levels are associated with reduced physical utility among cancer patients, whereas a higher education level was associated with a higher frequency of weekly exercise [3]. Generally, physical activity has been thought to be protective against hormone-related carcinoma since the physical activity reduces the intensity of endogenous hormones circulating throughout the body [26]. However, results regarding physical activity and the risk for prostate cancer are inconclusive.

Type of work: Men who are employed in environments that are not physically demanding or that expose them to a variety of elements may be at a higher risk for prostate cancer. A research study conducted by Heiskel et al. [27] found that working in transportation and communication industries correlates with the development of prostate cancer, whereas another study done in Japan, found positive correlations between the absence of prostate cancer and farm work [6].

A large unpublished European study has found that the risk for aggressive, advanced prostate cancer was lower among men in Europe with the most physically demanding (vigorous) occupations. Those with occupations that were less physically demanding, in Europe, dentists, religious workers, and administrators had the highest Standard Incidence Ratio (SIR) [4]. Additionally, men with occupations of higher economic prestige are at a higher risk for having prostate cancer than men with occupations that are of lower caliber [25]. Further research on the type of work schedule among men finds that rotating shift-workers are at a significantly higher risk for prostate cancer due to unhealthy sleep patterns [28].

Sleep amount: Sleep deprivation may be a key indicator of hormone-related carcinoma such as prostate cancer. This is due to the roles of serotonin and melatonin levels in the blood stream. Serotonin levels are highest during the daytime and regulate moods; sleep problems are correlated with deficient levels of serotonin and an imbalance of serotonin and melatonin [29].

Melatonin is associated with sleep patterns, and excretion of this hormone is the lowest during the day, and peaks as the night passes [28]. Therefore, a disruption in the circadian rhythm and a reduced melatonin secretion may be a strong indicator of prostate cancer development [28]. Additionally, the same study finds that melatonin may prohibit the growth of carcinoma through the regulation of transcription or other development factors.

Sun exposure and vitamin D: Kubo et al. [28], reports that a lack of exposure to ultraviolet rays can increase the risk of prostate cancer due to inadequate production of vitamin $\mathrm{D}$; vitamin $\mathrm{D}$ (1a, 25-dihydroxyvitamin $\mathrm{D}_{3}$ ) has been shown to be an inhibitor of prostate cancer cell propagation. Some dietary elements may provide vitamin $\mathrm{D}$; the primary type of vitamin $\mathrm{D}$ that circulates the body is 25 -hydroxyvitamin $\mathrm{D}$ [10]. Though vitamin $\mathrm{D}$ has shown to be protective against prostate carcinoma, an excessive volume of 25-hydroxyvitamin D circulating throughout the body can increase the risk of aggressive prostate cancer [30].

Diet: Some dietary elements have been shown to be influential in protecting against prostate carcinoma development. Learning what dietary elements are beneficial may be critical to middle-aged and older men; nutritional education may be instrumental in preventing prostate cancer. Further studies find that among older long-term survivors of cancer, more nutritional education is associated with a healthier diet [3].

Researchers [8] show that the consumption of raw, fresh vegetables may be a protective mechanism against prostate cancer. Studies further confirm that a diet that is rich in vegetables and low in fats are optimal for physical utility and prevention of the development of prostate cancer [31]. In addition, the Japanese take in high volumes of fish, soy and tofu a fact that led to the finding that isoflavones are a protective dietary element against prostate cancer [6].

Biologically, isoflavones are phytoestrogens (chemicals in plants) that behave like hormones. They have anti-estrogenic utilities that transpire in the reproductive system and could contribute to lowering the risk for hormone-related carcinomas (Linus Pauling Institute, 2010). Plants are most effective in lowering the risk for prostate cancer, whereas diets that are high in animal fat (red meats) may increase the risk [32].

A number of studies have reported positive correlations between fat intake and prostate carcinoma [33]. Consumption of bread and coffee may also increase the risk of developing prostate carcinoma [8]. According to previous research conducted by Adlercreutz [34], on hormones and biochemical mechanisms, high fiber intake and low fat diets lower the risk for prostate carcinoma since this diet assists in reducing circulating testosterone throughout the body.

Education: In health public health promotion and prevention, education has shown to be one of the most critical factors. In a case-control study comparative study, Schoonen et al. [35] found a strong relationship between prostate cancer risk and education level 
among middle-aged men. Recently, the American Cancer Society [5] conducted a study and found that African American men who had the equivalent of 12 years or less had a death rate that was two times as high as those who had an education level beyond 12 years. The study further finds that among white men, those that attained 12 years or less education had a death rate that was 1.5 time higher than those who had more than 12 years of education [5]. Death rates decreased noticeably among both African American and Caucasian American men with more than 13 years of education [15]. However, one study found that men who had a higher education level were more likely to have prostate cancer [36], which might be attributable to an increased rate of men having their prostate screened, and cancer detected because of an increase in education about prostate health.

Based on a survey conducted with 8,713 men in California, researchers found that men with higher socioeconomic position and higher education are more likely to pursue regular PSA screening [37]. Furthermore, Steenland et al. [38] found that men with more education were more likely to report that they had been PSA screened. With an increase in education, and increasing rate of those seeking preventive screening, the incidence rates are bound to increase. Men who at least had some college education had an incidence rate that was $15-19 \%$ higher than that among men who had 12 years or fewer of education [38]. This study found that higher education was associated with localized carcinoma such as prostate cancer. Again such findings may be attributable to higher rates of screening among those with higher education level.

Awareness about prostate health is a critical factor to maintaining prostate health. Prior studies by Denmark-Wahnefriedet al. [39] and Weinrich et al. [40] both found that African American men were less likely than Caucasian men to be educated about prostate health and screening. Many studies such as his imply that prostate cancer among African American men may be detected at a later stage, and the frequency of screenings may be unpredictable. Additionally, Konety et al. [7] found that the lack of educational materials regarding prostate cancer was a hindrance to the efficient delivery of healthcare and counseling to men; this lack of resources also prevents effective patientprovider communication (Table 1).

\section{Methods}

This study conducted a cross-cultural analysis comparing the relationship of incidences of prostate cancer across African American, Caucasian, and Mexican American, Puerto Ricans, and Other nonwhite Hispanic men from age 35 and above. The study examined the following: 1) ethnicity, 2) type of work, 3) levels of physical activity, 4) marital status, 5) education, 6) amount of sleep, and 7) amount of sun exposure. The study utilizes a secondary data analysis of the National Health Interview Survey (NHIS) [41] from years 2006, 2007, and 2008 combined. The sample of males-only $(N=21,646)$ was selected because men aged 35 and over have the highest prevalence of prostate cancer. Of the sample, 619 reported having prostate cancer, and another 1,401 reported having some other type of cancer.

The NHIS [41] in its Adult Health Behaviors section collects data on three levels of physical activity: moderate, vigorous, and strengthening activities. Varied data are gathered on the frequency of such activities. Because of concern with activity frequency, items were chosen that reflected frequency of exercise, respondent-reported participation an average of five days per week in: (1) moderate activity, (2) vigorous activity, and (3) strengthening activity. Analysis also employed a combined measure of requisite participation at any of the three levels.

\section{Data file creation techniques}

Researcher created and maintained a data file of variables. Adult Survey Data for each year 2006-2008 from the NHIS website was read into SAS. Some data was obtained from the Person Survey file and merged with the cases in the Adult Survey file. A work file was created for each year's survey, along with the addition of an indicator for the year of the survey. Retaining the entire data set in three yearly files allowed for selection of further analysis variables as needed. The work files were concatenated into the multi-year Adult-Survey file. Each procedure for the proposed multi-year analysis has been successfully employed in 3 year.

\section{General approach}

The contracted representative for collecting the National Health Interview Survey (NHIS) [41] data is the U.S. Census Bureau. NHIS data are collected via individual household interviews that are nationally administered by 600 interviewers. The 600 interviewers are supervised and rigorously trained in all 12 U.S. Census Bureau offices, nationally (National Health Interview Survey, 2008). The NHIS is conducted by using computer-assisted personal interviewing. The Computer Assisted Personal Interviewing (CAPI). The CAPI data collection method uses software that displays the questionnaire on the computer screen of each interviewer. Automatically, the computerized program guides the interviewer to pertinent questions determined by the answers to previous questions (National Health Interview Survey, 2008).

\section{Sample design}

Historically, the sample was redesigned and reformatted each decade. In 2006 there was a new sample design that was implemented, but the new design resembles the 1999-2005 NHIS design. This newly employed sample design has reduced the NHIS population sample by approximately $13 \%$ per year in 2007 and 2008.

To allow for more accurate and precise estimation of the health

Research hypotheses

\begin{tabular}{|c|c|}
\hline Hypothesis & Variable \\
\hline $\mathrm{H} 1$ & Age is a significant in predicting that men age 35 and over will have prostate cancer \\
\hline $\mathrm{H} 2$ & Ethnicity is correlated with predicting that men age 35 and over will have prostate cancer. \\
\hline $\mathrm{H} 3$ & Men who engage age 35 and over who engage in any type of physical activity are less likely to have prostate cancer. \\
\hline $\mathrm{H} 4$ & Being married is significant in predicting that a man age 35 or older will have prostate cancer. \\
\hline $\mathrm{H} 5$ & Sun exposure reduces the likelihood that men age $35-84$ and over will have prostate cancer \\
\hline $\mathrm{H} 6$ & Increased levels of education is correlated with having prostate cancer \\
\hline
\end{tabular}

This research study employs a secondary data analysis to test the hypotheses using 2006, 2007, and 2008 National Health Interview Adult Survey data. The NHIS survey is conducted by the U.S. Census Bureau and is collected to better measure the ever-changing population in the United States.

Table 1: It shows the research hypotheses tested in this research study. 
dynamics of the minority populations, oversampling of Hispanic, Black, and Asian populations was maintained in the 2006 redesign (NHIS, 2008). This study targets African American, Caucasian, Asian, Hispanic, and Native American men between the age of 35 and above. To ensure that older minority representatives had an optimal opportunity of being selected as a sampled adult, the sample selection protocol was revised (NHIS, 2008).

This sample population $(N=21,646)$ was selected because men aged 35 and over have the highest prevalence of prostate cancer. Of the sample, 619 reported that they had prostate cancer and 1,401 responded that they had some other form of cancer.

\section{Weighting information}

The population sampled is structured to where any one person chosen has a non-zero likelihood of being selected to participate in the survey. It is imperative to utilize the basic weight for accurate analysis of person record data. This is critical because NHIS employs a multistage design sample; this design is an attempt to signify the United States' inhabitant, non-institutionalized population (NHIS, 2008).

In the data files, the likelihood of selection and the adjustments for non-response and post stratification are shown.

Using weighted data, 2.74 percent of respondents reported prostate cancer compared to 2.86 percent of unweighted respondents. Weighted, 6.77 percent reported some other type of cancer compared to 6.74 percent unweighted. From this, one can see that the weighting corrects the prevalence estimates for prostate cancer more than it does for all other cancers.

\section{Instrumentation}

The NHIS data survey employs a questionnaire called the CAPI Reference Questionnaire. A significant amount of effort was expended to ensure the names of the variables were the same as the questions in the survey; this was not feasible with some cases.

The NHIS is a computer-based survey and is cumbersome to navigate. Therefore, strict measures to maintain quality have been taken. Any problems with the instrument were identified throughout the year and were resolved through changes in the wording of questions, skip patterns, or the addition of more questions, among other internal corrections. Changes to the 2007 instrument were minimal, allowing for only a single version of the NHIS over all four quarters for the year (National Health Interview Survey, 2008). See Appendix A for CAPI Reference Questionnaire instrument. The study utilized NHIS data from 2006, 2007, and 2008.

\section{Procedures}

The NHIS survey is a computerized and the adult sample survey used in this study includes 24,275 people for 2006, 23,393 people for 2007 , and 21,781 people for 2008. For 2007 the total response rate was 87.1 percent, with 8 percent who refused to be interviewed or whose interviews were incomplete or unacceptable. Some $4.9 \%$ of eligible respondents could not be located.

Timeline and Costs for Conducting the Study.

The NHIS is conducted over a course of four quarters, throughout a one-year period. Sampling and data collection was affected by the budget crisis that NHIS faced in 2007.

\section{Data analysis}

A quantitative analysis of the 2006, 2007, and 2008 NHIS data was employed in this study. The SUDAAN (Research Triangle Institute, 2004) and SAS were used and are acceptable research software packages that provided Taylor series linearization methods needed in NHIS variance estimation and testing of hypothesis for complex research. A logistic regression analysis was conducted to examine the probability of the occurrence each variable has on prostate cancer diagnosis. The logistic model helped determine which variables are critical in predicting a man's propensity to being diagnosed with prostate cancer. The dependent variable is prostate cancer diagnosis. The independent variables include the following: age, ethnicity, and levels of physical activity, marital status, amounts of sleep, sun exposure, and education.

In 2008 only, excluding other years, respondents were surveyed and asked whether or not they stayed in the shade on a warm, sunny day. This question was designed to determine how much sun exposure one acquired on average. The variable was re-coded so that those that reported that they sometimes, rarely, or never stayed in the shade on a warm sunny day equaled a value of 5 to indicate maximum sun exposure, while those who reported "always" or "sometimes" staying in the shade on a warm sunny day were assigned a value of 1 to indicate partial exposure. Accordingly, the analysis was run on the single year's data for 2008 .

\section{Results}

In this chapter are the descriptive statistics of the variables measured: age, ethnicity/race, marital status, physical activity, type of work, sleep, sun exposure, and education, and their effect on predicting prostate cancer diagnosis. The results of these variables and their predictions of having the disease are recorded in this section.

\section{Descriptive statistics}

The data are derived from a larger study conducted by the National Council for Health Statistics through the years 2006, 2007, and 2008. The sample $(21,646)$ was of men age 35 and older, and the average age of the respondents was 55 years with a standard deviation of 13 . Of the sample, 619 (approximately 3\%) reported that they were diagnosed with prostate cancer, with 29 cases missing, and 1,401 (approximately $6 \%$ ) reported having some other form of cancer; the average age at diagnosis for prostate cancer was 63 years.

In regard to the various ethnicities of the respondents, 19,386 (90\%) were white, 1,841 (8.5\%) reported that they were Mexican American, 320 (less than 1.5\%) were Puerto Rican (1.5\%) were Other Hispanic group, and 2,965 (13.7\%) were African American, and 1,256 (5.8\%) were non- Hispanic and non - African American, the other non - white group.

Of the sample, 70 percent reported that they were married, and 28 percent of the respondents engaged in any amount of physical activity each week. The questionnaire asked the respondents to report the amount of sleep they acquire each night from 0-24 hours, and the 21,097 respondents received an average of seven hours of sleep, with a standard deviation of 1.4 and 433 cases missing. Table 2 shows the descriptive statistics for the respondents of the questionnaire.

A frequency procedure was run to examine how many people had any type of cancer. Of the respondents surveyed from 2006, 2007, and $2008,21,646$ men listed their age as 35 or older. A total of 619 reported that they had been diagnosed with prostate cancer.

\section{Diagnosed with some other cancer}

Some men over the age of 35 reported having another form of 
Citation: Orakpo N (2014) Does Prostate Cancer Begin in the Prostate? Key Predictors of Having Disease. J Gerontol Geriat Res 3: 146. doi:10.4172/2167-7182.1000146

Page 7 of 12

\begin{tabular}{|c|c|c|c|}
\hline & $\begin{array}{l}\text { Weighted } \\
\text { Percentage }\end{array}$ & $\begin{array}{l}\text { Unweighted } \\
\text { Percentage }\end{array}$ & $\begin{array}{c}\text { Unweighted } \\
\text { Number }\end{array}$ \\
\hline \multicolumn{4}{|l|}{ Dependent Variables } \\
\hline Has Had Prostate Cancer & 2.74 & 2.86 & 619 \\
\hline Has Had Some Other Cancer & 6.77 & 6.74 & 1,457 \\
\hline Engages in Requisite Physical Activity & 28.7 & 28.0 & 5,892 \\
\hline \multicolumn{4}{|l|}{ Independent Variables } \\
\hline White, non-Hispanic & 73.7 & 66.0 & 14,285 \\
\hline Mexican American & 6.7 & 8.5 & 1,841 \\
\hline Puerto Rican & 1.2 & 1.5 & 320 \\
\hline Other Hispanic & 3.5 & 4.3 & 924 \\
\hline Black & 9.9 & 13.7 & 2,965 \\
\hline Other Nonwhite & 5.1 & 6.1 & 1,311 \\
\hline Married & 70.1 & 58.9 & 12,691 \\
\hline High School Degree & 83.6 & 81.0 & 17,396 \\
\hline Some College & 55.1 & 53.3 & 11,403 \\
\hline College Degree & 30.4 & 28.5 & 6,088 \\
\hline Interviewed in 2006 & 32.91 & 34.8 & 7,539 \\
\hline Interviewed in 2007 & 33.33 & 33.8 & 7,336 \\
\hline Interviewed in 2008 & 33.76 & 31.2 & 6,771 \\
\hline Interval Variables (Independent) & Mean & $\begin{array}{l}\text { Standard } \\
\text { Deviation }\end{array}$ & $\begin{array}{l}\text { Total } \\
\text { Number }\end{array}$ \\
\hline Age in Years & 53.9 & 13.5 & 21,646 \\
\hline Average Hours of Sleep per Night & 7.1 & 1.4 & 21,097 \\
\hline Total Number of Cases $=21,646$ & & & \\
\hline
\end{tabular}

Source: NCHS, 2006, 2007, 2008.

Multivariate Analysis

Dependent Variable: Prostate Cancer Diagnosis

Table 2: Descriptive statistics.

cancer. Of the sample $(N=21,646), 1,401$ reported that they were diagnosed with some other form of cancer besides prostate cancer. Of all who men who were 35 and older, approximately 6.5 percent had some other type of cancer. In creating this variable, there was a summary of 30 different cancer items aside from prostate cancer, with a value of 1 if a respondent reported any one or more of the 30 types of cancer. Because having prostate cancer may be the result of a general likelihood of having cancer, having some other type of cancer was considered a mediating variable in predicting the likelihood of prostate cancer. Table 3 shows findings predicting some other form cancer.

\section{Marital status}

Men over age 35 who reported being married were not significantly different on having any other form of cancer than men who were not married (odds ratio $=1.03$ ).

\section{Ethnicity}

African American men were nearly 70\% less likely to have any other form of cancer (odds ratio $=0.31$ ), and Mexican Americans were nearly $80 \%$ less likely to have some other form of cancer (odds ratio $=0.16$ ). Puerto Rican men were not significantly different from white men in terms of likelihood of being diagnosed with some other form of cancer (odds ratio=0.45). Other Hispanic groups were and 80 percent less likely to have some other form of cancer (odds ratio=0.20). All nonwhite groups are less likely to have some other type of cancer.

\section{Physical activity}

Respondents who reported that they engage in any amount of physical activity did not show any significant difference in being at risk for any type of cancer than men with no physical activity (odds ratio $=0.99$ ).

\section{Amount of sleep}

Respondents reported that they acquire 1-24 hours of sleep per night. Amount of sleep acquired did not prove to be a key predictor of some other form of cancer (odds ratio $=1.00$ ).

\section{Sun exposure}

The variable sun exposure is considered important but unfortunately was included only for the NHIS survey in the year 2008. Respondents who reported that they receive only partial sun exposure on warm sunny days recorded a 1 and those who received total sun exposure reported a 5 response. Men who reported having only partial sun exposure were $40 \%$ less likely to be diagnosed with some other form of cancer (odds ratio $=0.60$ ), and men who reported total sun exposure were $42 \%$ less likely to have some other form of cancer (odds ratio $=0.58$ ). Sun exposure was not a key predictor of some other form of cancer. Table 4 shows the relationship between some other form of cancer and sun exposure.

\section{Prostate cancer diagnosis}

This sample population $(N=21,646)$ was selected because men age 35 and over have the highest prevalence of prostate cancer. Of the sample, a subpopulation of 619 reported having prostate cancer, and 1,457 reported having some other type of cancer. Table 5 shows the relationships between various predictors and prostate cancer.

\section{Aging and prostate cancer diagnosis}

With each ten-year increase in age, the likelihood that a man

\begin{tabular}{|c|c|c|c|}
\hline Independent Variables and Effects & Odds Ratio & $\begin{array}{l}\text { Lower Limit } \\
95 \% \text { OR }\end{array}$ & $\begin{array}{l}\text { Upper Limit } \\
95 \% \text { OR }\end{array}$ \\
\hline Intercept & 0.00 & 0.00 & 0.01 \\
\hline Sleep & 1.00 & 0.99 & 1.00 \\
\hline Mexican American** & 0.16 & 0.10 & 0.25 \\
\hline Puerto Ricans* & 0.45 & 0.23 & 0.90 \\
\hline Other Hispanic Groups ${ }^{* *}$ & 0.20 & 0.11 & 0.38 \\
\hline African Americans ${ }^{* *}$ & 0.31 & 0.23 & 0.42 \\
\hline Other Non-White Groups ${ }^{* *}$ & 0.31 & 0.19 & 0.51 \\
\hline Age in 10 years $* *$ & 1.87 & 1.79 & 1.95 \\
\hline Any Physical Activity & 0.99 & 0.85 & 1.15 \\
\hline Married & 1.03 & 0.89 & 1.19 \\
\hline High School Degree & 1.06 & 0.84 & 1.34 \\
\hline Some College* & 1.22 & 1.01 & 1.47 \\
\hline College Degree & 1.13 & 0.95 & 1.35 \\
\hline$N=20,734$ & ${ }^{*} p<0.05$ & ${ }^{* *} p<0.01$ & \\
\hline
\end{tabular}

Table 3: Predictors of some other cancer.

\begin{tabular}{|c|c|c|c|}
\hline Independent Variables and Effects & Odds Ratio & $\begin{array}{l}\text { Lower Limit } \\
95 \% \text { OR }\end{array}$ & $\begin{array}{l}\text { Upper Limit } \\
95 \% \text { OR }\end{array}$ \\
\hline Intercept & 0.00 & 0.00 & 0.01 \\
\hline Sleep & 1.02 & 0.93 & 1.11 \\
\hline Mexican American** & 0.19 & 0.08 & 0.45 \\
\hline Puerto Ricans & 0.37 & 0.10 & 1.38 \\
\hline Other Hispanic Groups ${ }^{* *}$ & 0.23 & 0.08 & 0.65 \\
\hline African Americans ${ }^{\star *}$ & 0.31 & 0.17 & 0.57 \\
\hline Other Non-White Groups ${ }^{* *}$ & 0.30 & 0.13 & 0.70 \\
\hline Age in 10 years ${ }^{* *}$ & 1.76 & 1.60 & 1.95 \\
\hline Married & 0.99 & 0.78 & 1.24 \\
\hline Partial Sun Exp* & 0.60 & 0.40 & 0.92 \\
\hline Maximum Sun Exp* & 0.58 & 0.37 & 0.89 \\
\hline$N=6,379$ & ${ }^{*} p<0.05$ & ${ }^{* *} p<0.01$ & \\
\hline
\end{tabular}

Table 4: Sun Exposure Predicting Other Cancer (2008 only). 
Citation: Orakpo N (2014) Does Prostate Cancer Begin in the Prostate? Key Predictors of Having Disease. J Gerontol Geriat Res 3: 146. doi:10.4172/2167-7182.1000146

Page 8 of 12

would be diagnosed with prostate cancer tripled (odds ratio=2.95) The correlation between the increase in age every ten years and having prostate cancer was significant as advancing age showed to be associated with predicting prostate cancer ( $p$-value $=0.000$ ).

\section{Marital status and prostate cancer diagnosis}

Marital status was a key predictor of early detection of prostate cancer (odds ratio $=1.52 ; \mathrm{p}<0.01$ ) Controlling for any other cancer revealed no significant difference than those who were married to be diagnosed with prostate cancer.

\section{Ethnicity and prostate cancer diagnosis}

African American men were $90 \%$ more likely than whites to be diagnosed with prostate cancer (odds ratio=1.90). Mexican Americans were only $8 \%$ more likely than whites to have prostate cancer (odds ratio=1.08). Puerto Rican men were just as likely as white men to have prostate cancer (odds ratio $=1.00$ ), and Other Hispanic groups were $11 \%$ more likely than whites to have prostate cancer (odds ratio=1.11). Other non-white men were $39 \%$ less likely than whites to be diagnosed with prostate cancer (odds ratio $=0.61$ ).

\section{Physical activity and prostate cancer diagnosis}

Respondents were asked if they engaged in light-moderate, vigorous or strengthening activity. The variable for physical activity was re-coded to included "any" level of physical activity. Physical activity did not prove to have a significant effect on prostate cancer diagnosis.

\section{Sleep amount and prostate cancer diagnosis}

Respondents were asked how many hours of sleep they received per night. The Logitmodel was constructed in order to determine whether or not the amount of sleep one acquired per night was a good predictor of prostate cancer diagnosis. Sleep was not significant in predicting prostate cancer or any other cancer.

\section{Some other cancer and prostate cancer diagnosis}

In the study including "Some Other Cancer" as a mediator variable was to control for general effects of predictors on cancer in general, as opposed to only prostate cancer.

Some effects of predictive factors may be on cancer overall, rather than specifically on prostate cancer.Adding Some Other Cancer as an independent variable controls for this, allowing assessment of effects of other predictors specifically on prostate cancer.

Using some other cancer as a predictor of prostate cancer showed that men who had some other type of cancer were 41 percent more likely to have also have prostate cancer (odds ratio=1.41). Table 6 shows the effect of having some other cancer and prostate cancer.

Most importantly, critical to the study are any differences in coefficients for factors other than Some Other Cancer between the Tables 5 and 6. Comparing the two tables, it appears that there is no real change, meaning that effects on cancer in general do not mediate effects on prostate cancer, only strengthening the findings associated with prostate cancer.

\section{Sun exposure and prostate cancer diagnosis}

Table 6 shows that those who reported maximum sun exposure on warm sunny days were almost $50 \%$ less likely to be diagnosed with prostate cancer than those who were partially exposed to the sun (odds ratio=0.54). Partial sun exposure yielded a positive relationship with

\begin{tabular}{|c|c|c|c|}
\hline Independent Variables and Effects & Odds Ratio & $\begin{array}{c}\text { Lower Limit } \\
95 \% \text { OR }\end{array}$ & $\begin{array}{c}\text { Upper Limit } \\
95 \% \text { OR }\end{array}$ \\
\hline Intercept & 0.00 & 0.00 & 0.00 \\
\hline Sleep & 0.99 & 0.98 & 1.01 \\
\hline Mexican American & 1.08 & 0.59 & 1.99 \\
\hline Puerto Ricans & 1.00 & 0.33 & 2.98 \\
\hline Other Hispanic Groups & 1.11 & 0.58 & 2.12 \\
\hline African Americans** & 1.90 & 1.40 & 2.57 \\
\hline Other Non-White Groups & 0.61 & 0.33 & 1.11 \\
\hline Age in 10 years** & 2.95 & 2.75 & 3.17 \\
\hline Any Physical Activity & 1.01 & 0.79 & 1.29 \\
\hline Married & 1.52 & 1.23 & 1.88 \\
\hline High School degre* & 1.44 & 1.05 & 1.99 \\
\hline Some College & & 1.06 & 1.86 \\
\hline College Degree & 1.40 & 0.79 & 1.43 \\
\hline N 20,734 & 1.06 & & \\
\hline
\end{tabular}

Table 5: Predictors of prostate cancer.

\begin{tabular}{|c|c|c|c|}
\hline Independent Variables and Effects & Odds Ratio & $\begin{array}{l}\text { Lower Limit } \\
95 \% \text { OR }\end{array}$ & $\begin{array}{l}\text { Upper Limit } \\
\text { 95\% OR }\end{array}$ \\
\hline Intercept & 0.00 & 0.00 & 0.00 \\
\hline Sleep & 0.99 & 0.98 & 1.01 \\
\hline Mexican American & 1.13 & 0.61 & 2.08 \\
\hline Puerto Ricans & 1.04 & 0.35 & 3.12 \\
\hline Other Hispanic Groups & 1.15 & 0.60 & 2.20 \\
\hline African Americans ${ }^{* *}$ & 1.98 & 1.45 & 2.69 \\
\hline Other Non-White Groups & 0.63 & 0.34 & 1.17 \\
\hline Age in 10 years $^{* *}$ & 2.90 & 2.69 & 3.13 \\
\hline Any Physical Activity & 1.01 & 0.79 & 1.29 \\
\hline Married $^{\star *}$ & 1.52 & 1.23 & 1.87 \\
\hline High School Degree* & 1.45 & 1.05 & 2.00 \\
\hline Some College* & 1.39 & 1.05 & 1.84 \\
\hline College Degree & 1.13 & 0.79 & 1.42 \\
\hline Some Other Cancer ${ }^{*}$ & 1.41 & 1.05 & 1.31 \\
\hline$N=20,734$ & ${ }^{*} p<0.05$ & ${ }^{* *} p<0.01$ & \\
\hline
\end{tabular}

Table 6: Some other cancer predicting prostate cancer.

prostate cancer diagnosis. Maximum sun exposure was a significant in predictor prostate cancer diagnosis and showed a negative relationship, indicating that the more sun exposure reduced the likelihood that one would be diagnosed with prostate cancer. Table 7 shows the relationship between sun exposure and prostate cancer diagnosis. The men that reported that they rarely are exposed to the sun on a warm sunny day were slightly more than $20 \%$ more likely than men who were totally exposed to the sun to have prostate cancer (odds ratio=1.23).

\section{Education and prostate cancer}

Education was used as an independent variable in this study. The data concludes that having a high school education or at least some college was significantly associated with prostate cancer, but showed a positive effect. This may indicate that men who have at least a high school education may be more likely to be screened for prostate cancer and report it. Men over the age of 35 who had at least 12 years of education were more than $40 \%$ more likely than those without 12 years of education to have prostate cancer (odds ratio=1.45). Furthermore, men over the age of 35 that reported that they had some college education were nearly $40 \%$ more likely than those with no college to have early detection of prostate cancer (odds ratio $=1.39$ ). Finally, men who graduated from college were approximately $13 \%$ more likely to have early detection of prostate cancer than those who did not have degree (odds ratio=1.13). 
Citation: Orakpo N (2014) Does Prostate Cancer Begin in the Prostate? Key Predictors of Having Disease. J Gerontol Geriat Res 3: 146. doi:10.4172/2167-7182.1000146

Page 9 of 12

\begin{tabular}{|c|c|c|c|}
\hline Independent Variables and Effects & Odds Ratio & $\begin{array}{c}\text { Lower Limit } \\
95 \% \text { OR }\end{array}$ & $\begin{array}{c}\text { Upper Limit } \\
95 \% \text { OR }\end{array}$ \\
\hline Intercept & 0.00 & 0.00 & 0.01 \\
\hline Sleep & 0.90 & 0.80 & 1.00 \\
\hline Mexican American & 0.73 & 0.30 & 1.76 \\
\hline Puerto Ricans & 1.82 & 0.58 & 6.50 \\
\hline Other Hispanic Groups & 0.80 & 0.26 & 2.44 \\
\hline African Americans & 1.43 & 0.84 & 2.45 \\
\hline Other Non-White Groups & 0.91 & 0.36 & 2.35 \\
\hline Age in 10 years** & 2.81 & 2.48 & 3.08 \\
\hline Any Physical Activity & 1.14 & 0.80 & 1.67 \\
\hline Married** & 1.68 & 1.19 & 2.38 \\
\hline Partial Sun Exp. & 1.23 & 0.68 & 2.24 \\
\hline Maximum Sun Exp* & 0.54 & 0.31 & 0.96 \\
\hline$N=6,378$ & $* p<0.05$ & $* * 0<0.01$ & \\
\hline
\end{tabular}

Table 7: Sun exposure predicting prostate cancer (2008 only).

\section{Summary of results}

In Table 8 below are the tested hypotheses and effects of each variable on the likelihood a man over the age of 35 would have prostate cancer.

\section{Conclusion}

The findings in this study may provide a perspective on how age, ethnicity, marital status, physical activity, sleep, and sun exposure influence prostate cancer development. It may further assist in identifying risk of prostate cancer among men age 35 and older. A priority of the study was to catalyze the development of prostate cancer prevention programs and interventions, and to contribute to the successful aging of men globally.

Notably, the data supported six out of seven of the hypotheses. The following is a discussion of hypotheses, the variable and its effects.

\section{Age}

The study found that every ten-year increase in age yields a tripled likelihood for diagnosis, showing advancing age to be a strong predictor of prostate cancer diagnosis. In short, as a man's age advances, he is more likely to develop prostate cancer. This finding supports the literature in that as age increases, there may be an increase in the amount of Prostate-Specific Antigen in the blood; an elevated level of PSA may indicate prostate cancer (The Cleveland Clinic Urological Institute, 2006). The data in the study supports the hypothesis that age is a key predictor of prostate cancer. Chiu et al. [10] found that one out of every six men between the age of 60 and 80 will battle prostate cancer. Increasing age is a strong predictor that men over the age of 35 will develop prostate cancer.

\section{Marital status}

In the data survey there was no variable for sexual activity, however the study made the assumption that being married would have a positive effect on prostate cancer diagnosis since those with a spouse may be more encouraged to do routine prostate exams. Those who are married may also be sexually active, indicating that the man has a healthy, active prostate. Moreover, marital status was a significant predictor for prostate cancer. Marital status had a positive effect on predicting prostate cancer, meaning that if more men are being screened because they are receiving spousal support and encouragement, then the reported incidence is likely to increase. Controlling for any other type of cancer did not show any results that were substantially different.

\section{Race/ethnicity}

According to the Center for Disease Control (2010), since 1975, African Americans have had and continue to have the highest incidence of prostate cancer. In this research study, the data analysis supported this finding as African Americans were much more likely than whites and all other ethnic groups to have prostate cancer, and yet much less likely to any other form of cancer. The findings in this study support the literature and support previous research that ethnicity is a key predictor for prostate cancer. Other Hispanic groups were more likely than whites to have prostate cancer. However, other non-whites were much less likely than white men to have prostate cancer. Overall, ethnicity, in this particular study and previous studies proved to be a strong predictor that men, namely African American and Caucasian American have a higher prevalence of prostate cancer than other races and ethnic groups.

\section{Physical activity}

Physical activity did not prove to be a key factor in reducing the likelihood that a man would be diagnosed with prostate cancer in this study. The findings are inconsistent with The British Regional Heart Foundation (2007) who discovered that regular moderate-vigorous activity strongly decreases the risk for prostate cancer. Inversely, a study conducted by Gallus et al. [7] found that the results regarding physical activity and the risk for prostate cancer are not related. Type of Work was shown to have an effect on prostate cancer in a large European study. This may be due to the cultural differences in diet and exercise among European men compared to American men. According to Johnsen et al. (2009), the men with the most physically demanding occupations (vigorous) are less likely to have prostate cancer. In this particular study, it is not clear why physical activity would not show an effect, although it may be that the prevalence of prostate cancer was simply too low for an effect to show up even with only 619 cases.

\section{Sleep amount}

Kubo et al. [24] states that the excretion of melatonin during the night peaks and this excretion of melatonin hormone may be protective against the development of prostate cancer as well as against other growth factors. However, in this particular study sleep was not a key predictor of prostate cancer diagnosis, and therefore the findings do not support the literature nor do the findings support the hypothesis

\begin{tabular}{|c|c|c|c|}
\hline Hypotheses & Prediction & Effect \\
\hline $\mathrm{H}_{1}$ & $\begin{array}{c}\text { Advancing age increases the likelihood that } \\
\text { men age } 35 \text { and over will be diagnosed with } \\
\text { prostate cancer }\end{array}$ & $(+)$ & $(+)$ \\
\hline $\mathrm{H}_{2}$ & $\begin{array}{c}\text { Ethnicity is key in predicting that men will } \\
\text { have prostate cancer. }\end{array}$ & $(+)$ & $(+)$ \\
\hline $\mathrm{H}_{3}$ & $\begin{array}{c}\text { Engaging in any type of physical activity is } \\
\text { reduces the likelihood that men age 35 and } \\
\text { over will have prostate cancer. }\end{array}$ & $(-)$ & $\begin{array}{c}\text { None } \\
\text { detected }\end{array}$ \\
\hline $\mathrm{H}_{4}$ & $\begin{array}{l}\text { Being married increases the likelihood that } \\
\text { a man age 35 and over will have prostate } \\
\text { cancer. }\end{array}$ & $(+)$ & $(+)$ \\
\hline $\mathrm{H}_{5}$ & $\begin{array}{l}\text { Low amount of sleep acquired increases the } \\
\text { likelihood that a man over the age of 35 will } \\
\text { have prostate cancer. }\end{array}$ & $(+)$ & $\begin{array}{c}\text { None } \\
\text { detected }\end{array}$ \\
\hline $\mathrm{H}_{6}$ & $\begin{array}{r}\text { Sun exposure reduces the likelihood that } \\
\text { a man age 35 and over will have prostate } \\
\text { cancer will have prostate cancer. }\end{array}$ & $(-)$ & $(-)$ \\
\hline $\mathrm{H}_{7}$ & $\begin{array}{c}\text { Education increases the likelihood that men } \\
\text { age 35 and over }\end{array}$ & $(+)$ & $(+)$ \\
\hline
\end{tabular}

Table 8: Hypotheses and variable effects. 
that sleep amount is a significant predicting that a man over the age of 35 will have prostate carcinoma.

\section{Some other cancer}

Some men responded that they had some other form of cancer. The study found that men who reported that they had some other form of cancer were much more likely to have prostate cancer. This could be due to the fact that prostate cancer is the most prevalent carcinoma among men in general (ESMO, 2005). Furthermore, having some other cancer may be due to the spreading of prostate cancer throughout the body. Therefore, a man who has any kind of carcinoma is most likely going to have prostate cancer, or he may be diagnosed with prostate cancer and another cancer.

\section{Sun exposure}

Exposure to the sun can be a protective mechanism against prostate cancer. This study found that on warm, sunny days, a man who was totally exposed to the sun was less likely to be having prostate cancer than those who were rarely in the sun. The findings in the research study are consistent with the literature and supports the hypothesis that exposure to ultraviolet rays can actually decrease the risk of prostate cancer. Perhaps this is due to the adequate production of vitamin D. According to Kubo et al. [24], vitamin D (1a, 25-dihydroxyvitamin $\mathrm{D}_{3}$ ) is an inhibitor of prostate cancer cell promulgation. Henceforth, it is imperative that men receive maximum sun exposure on warm sunny days. Excessive exposure, like tanning, however, may increase the risk for other cancer such as skin carcinoma. This is a significant finding and sun exposure is a key factor in reducing the risk for prostate cancer according to this specific study, and needs to be explored in more depth.

\section{Education}

Education proved to have a positive effect on the likelihood that a man over the age of 35 would detect prostate cancer. In this study in particular, the findings were consistent with the literature in that men who had at least 12 years of education were more likely to know they have the disease than men with less than 12 years of education. Vidarsdottir et al. [32] found that men who had a higher education level were at a higher risk for having prostate cancer (doesn't make sense). This positive effect may be attributed to an increased rate of men having their prostate screened because of an increase in education about prostate health. According to American Cancer Society (2010), men with less than 12 years or education had nearly twice the mortality rate of those who had 12 years of education or beyond. Men, who have 13 years or more of education, are more likely to be proactive about being screened for prostate cancer [12]. Additionally, men who have some college education and a higher socioeconomic position are more likely to pursue regular PSA screening [33]. The positive effect is associated with more education, indicating a higher likelihood that prostate cancer may be detected among men who have high school education or greater. This study supports the findings that more education yields an increased likelihood that prostate cancer will be detected among men over the age of 35 .

\section{Implications and Applications}

\section{Implications}

The study found that key predictors that a man will be diagnosed with prostate cancer is dependent upon his age, marital status ethnicity, whether or not he has another form of cancer, maximum sun exposure, and education level. Most studies provide evidence on the incidence of prostate cancer among older men over the age of 65 . However, the significance of this study was that it included younger and middle-aged men from age 35 and older. The implications are related to the fact that there is no single cause of prostate cancer and that more research is critical to fully understand a disease that is most popular among men. More research will provide a better understanding and a more competent health care system that serves aging men.

Assessments, preventive screenings, and treatments can be provided if more attention is given to prostate cancer. This focus can influence policymakers to help advocate and create policy that supports adequate medical attention and interventions for men who are at-risk, diagnosed, or survivors of prostate cancer.

\section{Applications}

For applied gerontologists, oncologists, and practitioners in the field of aging it means that there needs to be more preventive health programs for younger men before the onset of prostate cancer. Such programs should include prostate specific antigen tests, dietary modifications, vitamin $\mathrm{D}$ supplements to protect against the proliferation of prostate cancer cells, and the promotion of safe sun exposure. Though maximum sun exposure may reduce the likelihood that a man will have prostate cancer, there are still risks for developing other types of cancers such as non-melanoma carcinoma (American Cancer Society, 2010). According to the American Cancer Society (2010), Skin cancer is the third most common type of cancer among Americans with fair skin. The American Cancer Society (2010) states that it safest to avoid the sun from $10 \mathrm{a}$ to $4 \mathrm{pm}$ when the ultraviolet rays are the most intense. However, African Americans who have darker complexions (more melanin) may benefit from maximum sun exposure to produce more vitamin $\mathrm{D}$.

Furthermore, the development of preventive health programs that include early detection prostate screenings would prepare African American men to age well and could possibly reduce the cancerrelated mortality rates among fathers and grandfathers. According to the Center for Disease Control and Prevention (2010) African American men are most likely to have prostate cancer and most likely than all other ethnic groups to die from it. This indicates that more campaigns should push for the revision of clinical practice guidelines to include cultural competency in medicine, enabling physicians and other healthcare practitioners to openly communicate with patients. For example, when physicians are dealing with African American male patients, performing a prostate specific antigen test or digital exam should be an inherent part of the annual screening process. Figure 3 shows the key predictors of prostate cancer diagnosis as it pertains to this study, and it shows the interventions/treatments for prostate cancer patients.

\section{Recommendation for Future Research}

More studies conducted on prostate cancer should include men younger than 64 since men who have prostate cancer at a younger age most likely have a family history of it. Though the data survey instrument did not include a variable for family history, the literature suggests that men are more likely to be diagnosed with prostate cancer at a younger age if a predecessor in the family has the disease. Insurance entities should provide incentives for all men who are proactive in caring for their prostate and who take an active role in maintaining their prostate health. Such incentives should be inherent in the new Healthcare Plan, and could include rebates, affordable or free annual exams that are preventive.

Furthermore, interventional studies that include Asian Americans 
Citation: Orakpo N (2014) Does Prostate Cancer Begin in the Prostate? Key Predictors of Having Disease. J Gerontol Geriat Res 3: 146. doi:10.4172/2167-7182.1000146

\section{KEY PREDICTORS}

Age

Ethnicity

Marital status

Some other cancer

Sun exposure

Diet

Education

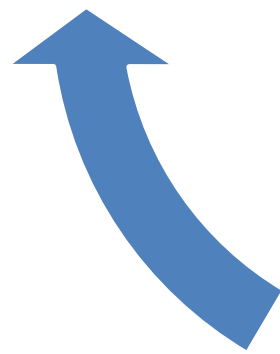

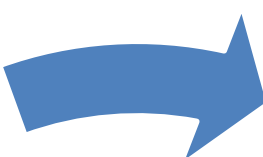

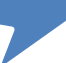

PREVENTIVE
MEDICINE:

Digital screenings

Biopsy

PSA blood tests

Education

\section{INTERVENTIONS}

Policy

Research

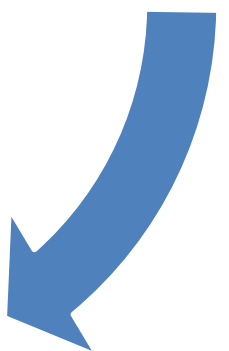

Fund men' s heatlh

Cultural competency

Figure 3: Key predictors, preventive methods, research and policy.

and Native Americans, who have the lowest incidence of prostate cancer, could provide evidence on which dietary elements, modifications, and other lifestyle variables could be beneficial to African Americans and White Americans, where the incidence is highest. Additionally, to ensure further and stronger research in this area of oncology, the sampling size should be larger and the study should be longitudinal in order to better understand more of the possible predictors and the long-term effects of prostate cancer. Family history, Type of Work, level of income/class, and diet were not included in this particular study, but may prove to be strong predictors in a larger sample. Education was also a key a predictor, but was used as a control in this study.

Moreover, in-depth, longitudinal research is critical in order to comprehend the long-term effects of sun exposure on prostate cancer. In attempt to reduce or eliminate disparity, more extensive research on prostate cancer may also provide implications on the amount of safe sun exposure by ethnic group. If African Americans are less likely to have any other form of cancer, as shown in this study, maximum sun exposure could be show to be safe, and perhaps help reduce the likelihood that African American men would have prostate cancer.

Finally, service, advocacy, and education, as stated by the American Cancer Society (2010), may be useful mechanisms in reducing the incidence of prostate cancer among African American men. Policymakers should push for more funding for mass marketing and campaigns to occur in the predominantly African American mega churches and barber shops using the research model designed and implemented by the University of Texas Southwestern Medical Center (2003) in Dallas, Texas. With this research study, African American men could receive free haircut if they agreed to allow the barber to take their blood pressure. The barber shop is a frequent meeting place for African American men, and the aim of this research, as stated by Dr. Ron Victor, is to make hypertension education and screening an inherent element of the visit to the barbershop (University of Texas
Southwestern Medical Center, 2003). Such research studies have proven valuable and have been made possible through research grant funding for Minority Health from the Texas Higher Education Coordinating Board (University of Texas Southwestern Medical Center, 2003). With such advocacy, these men will have the opportunity to age successfully.

\section{Limitations of the Study}

As a result of the budget cut in 2006-2007, the Division of Health Interview Statistics reduced the National Health Interview Survey (NHIS) sample; the reduction of the sample was an attempt to simply save money. During the period of July - September of 2007, the NHIS sample was cut by $50 \%$. Additionally, approximately $13 \%$ of the homes in the NHIS sample were unassigned to the investigators. This reduction is in addition to a steady $13 \%$ reduction that occurred in 2006 (NHIS, 2008). A variable for income was not included in the survey instrument, and therefore, the income variable had to be imputed based on a number of independent variables. Previous research studies find that occupation, family history, and diet are strong predictors of prostate cancer (American Cancer Society, 2010). However, there were no measures for type of work, family history, or dietary elements in the NHIS data set and survey instrument, and therefore, these variables could not be studied in this project.

\section{Acknowledgements}

I would like to thank my committee for their dedication, patience and insight for this project. Special thanks are owed to the National Health Interview Survey fo making the data available.

\section{References}

1. Wannamethee SG, Shaper AG, Walker M (2001) Physical activity and risk of cancer in middle-aged men. $\mathrm{Br} \mathrm{J}$ Cancer 85: 1311-1316.

2. Bowling A (2007) Aspirations for older age in the 21st century: what is successful aging? Int J Aging Hum Dev 64: 263-297.

3. Mosher CE, Sloane R, Morey MC, Snyder DC, Cohen HJ, et al. (2009) 
Citation: Orakpo N (2014) Does Prostate Cancer Begin in the Prostate? Key Predictors of Having Disease. J Gerontol Geriat Res 3: 146. doi:10.4172/2167-7182.1000146

Page 12 of 12

Associations between lifestyle factors and quality of life among older long-term breast, prostate, and colorectal cancer survivors. Cancer 115: 4001-4009.

4. Pukkala et al. Surveillance, Epidemiology, and End Results (SEER) Program, National Cancer Institute (NCl) 1975-1991 = SEER 9; 1992-2005 = SEER 13.

5. American Cancer Society (2010) Cancer Facts and Figures, 2010.

6. Nagata Y, Sonoda T, Mori M, Miyanaga N, Okumura K, et al. (2007) Dietary isoflavones may protect against prostate cancer in Japanese men. J Nutr 137: 1974-1979.

7. Konety BR, Sharp VJ, Raut H, Williams RD (2008) Screening and management of prostate cancer in elderly men: the lowa Prostate Cancer Consensus. Urology 71: 511-514.

8. Gallus S, Foschi R, Talamini R, Altieri A, Negri E, et al. (2007) Risk Factors for Prostate Cancer in Men Aged Less Than 60 Years: A Case-Control Study from Italy. Urology 70: 1121-1126.

9. Denberg TD, Glodé LM, Steiner JF, Crawford ED, Hoffman RM (2006) Trends and predictors of aggressive therapy for clinical locally advanced prostate carcinoma. BJU Int 98: 335-340.

10. Fu L, Lee CC (2003) The circadian clock: pacemaker and tumour suppressor. Nat Rev Cancer 3: 350-361.

11. Prostate Cancer 2010

12. Cleveland Urological Institute (2006) The. Prostate Cancer Basics

13. Chiu BC, Anderson JR, Corbin D (2005) Predictors of prostate cancer screening among health fair participants. Public Health 119: 686-693.

14. Villeneuve PJ, Johnson KC, Kreiger N, Mao Y (1999) Risk factors for prostate cancer: results from the Canadian National Enhanced Cancer Surveillance System. The Canadian Cancer Registries Epidemiology Research Group. Cancer Causes Control 10: 355-367.

15. Platz E, Giovannucci E (2006) Prostate cancer, Cancer Epidemiology and Prevention. (3rdedn). Oxford: Oxford University Press: 1128-1150.

16. Breen N, Wagener DK, Brown ML, Davis WW, Ballard-Barbash R (2001) Progress in cancer screening over a decade: results of cancer screening from the 1987, 1992, and 1998 National Health Interview Surveys. J Natl Cancer Inst 93: 1704-1713.

17. Hoffman RM, Gilliland FD, Eley JW, Harlan LC, Stephenson RA, et al. (2001) Racial and ethnic differences in advanced-stage prostate cancer: the Prostate Cancer Outcomes Study. J Natl Cancer Inst 93: 388-395.

18. Etzioni R, Berry KM, Legler JM, Shaw P (2002) Prostate-specific antigen testing in black and white men: an analysis of medicare claims from 19911998. Urology 59: 251-255.

19. Fowke JH, Schlundt D, Signorello LB, Ukoli FA, Blot WJ (2005) Prostate cancer screening between low-income African-American and Caucasian men. UrolOncol 23: 333-340.

20. U.S. Cancer Statistics Working Group. United States Cancer Statistics: 1999_ 2005 Incidence and Mortality Web-based Report.Atlanta (GA): Department of Health and Human Services, Centers for Disease Control and Prevention, and National Cancer Institute;

21. Liu L, Cozen W, Bernstein L, Ross RK, Deapen D (2001) Changing relationship between socioeconomic status and prostate cancer incidence. J Natl Cancer Inst 93: 705-709.

22. Roetzheim RG, Pal N, Tennant C, Voti L, Ayanian JZ, et al. (1999) Effects of health insurance and race on early detection of cancer. J Natl Cancer Inst 91 : 1409-1415.

23. Bergman J, Gore JL, Saigal CS, Kwan L, Litwin MS (2009) Partnership and outcomes in men with prostate cancer. Cancer 115: 4688-4694.
24. Banthia R, Malcarne VL, Varni JW, Ko CM, Sadler GR, et al. (2003) The effects of dyadic strength and coping styles on psychological distress in couples faced with prostate cancer. J Behav Med 26: 31-52.

25. Lund Nilsen TI, Johnsen R, Vatten LJ (2000) Socio-economic and lifestyle factors associated with the risk of prostate cancer. $\mathrm{Br} \mathrm{J}$ Cancer 82: 1358-1363.

26. Thune I, Lund E (1994) Physical activity and the risk of prostate and testicular cancer: a cohort study of 53,000 Norwegian men. Cancer Causes Control 5: 549-556.

27. Heiskel H, Seidler A, Bickeböller R, Elsner G (1998) [Work-related risk factors of prostate carcinoma: results of a case-control study]. SozPraventivmed 43: 282-292.

28. Kubo T, Ozasa K, Mikami K, Wakai K, Fujino Y, et al. (2006) Prospective cohort study of the risk of prostate cancer among rotating-shift workers: findings from the Japan collaborative cohort study. Am J Epidemiol 164: 549-555.

29. Carol H (2008) The Secrets of Serotonin: the natural hormone that curbs food and alcohol cravings, reduces pain, and elevates your mood, St. Martin's Press, New York, NY.

30. Ahn J, Peters U, Albanes D, Purdue MP, Abnet CC, et al. (2008) Serum Vitamin D Concentration and Prostate Cancer Risk: a nested case-control study. J Natl Cancer Inst 100: 796-804.

31. Demark-Wahnefried W, Clipp EC, Morey MC, Pieper CF, Sloane R, et al (2004) Physical function and associations with diet and exercise: Results of a cross-sectional survey among elders with breast or prostate cancer. Int $J$ BehavNutrPhys Act 1: 16.

32. Giovannucci E, Rimm EB, Colditz GA, Stampfer MJ, Ascherio A, et al. (1993) A prospective study of dietary fat and risk of prostate cancer. J Natl Cancer Inst 85: 1571-1579.

33. Ellison LF, Stokes J, Gibbons L, Lindsay J, Levy I, et al. (1998) Monograph series on aging-related diseases: X. Prostate cancer. Chronic Dis Can 19: 1-18.

34. Adlercreutz H (1990) Western diet and Western diseases: some hormonal and biochemical mechanisms and associations. Scand J Clin Lab Invest Suppl 201 3-23.

35. Schoonen WM, Salinas CA, Kiemeney LA, Stanford JL (2005) Alcohol consumption and risk of prostate cancer in middle-aged men. Int J Cancer 113: 133-140.

36. Vidarsdottir H, Gunnarsdottir HK, Olafsdottir EJ, Olafsdottir GH, Pukkala E, et al. (2008) Cancer risk by education in Iceland; a census-based cohort study. ActaOncol 47: 385-390.

37. Spencer BA, Babey SH, Etzioni DA, Ponce NA, Brown ER, et al. (2006) A population-based survey of prostate-specific antigen testing among California men at higher risk for prostate carcinoma. Cancer 106: 765-774.

38. Steenland K, Rodriguez C, Mondul A, Calle EE, Thun M (2004) Prostate cancer incidence and survival in relation to education (United States). Cancer Causes Control 15: 939-945.

39. Demark-Wahnefried W, Strigo T, Catoe K, Conaway M, Brunetti M, et al. (1995) Knowledge, beliefs, and prior screening behavior among blacks and whites reporting for prostate cancer screening. Urology 46: 346-351.

40. Weinrich SP, Boyd MD, Weinrich M, Greene F, Reynolds WA Jr, et al. (1998) Increasing prostate cancer screening in African American men with peereducator and client-navigator interventions. J Cancer Educ 13: 213-219.

41. National Center for Health Statistics (NCHS) ( 2002) National Health Interview Survey (NHIS) Public Use Data Release NHIS Survey Description. Hyattsville MD: NCHS Division of Health Interview Statistics. 